\title{
COMPARATIVE STUDY OF HERMIT CRAB RESPONSES TO SHELL-RELATED CHEMICAL CUES
}

\author{
BRIAN A. HAZLETT \\ Deparmen of Biology \\ University of Michigan \\ Ann Arbor, Michigan, 48109 \\ Depariment of Marine Biology \\ James Cook University \\ Tounsville, QLD, Australia
}

(Received February 16, 1996; accepted July 22. 1996)

\begin{abstract}
The responses of Australian hermil crabs to two types of shellrelated odor cues were compared. Introduction of gastropod snail odor elicited an increase in grasping of shells in all four species tested (Clibanarius infraspinatus, $C$. taenialus, $C$. virescens, and Diogenes avarus). However, the magnitude of response in the case of $C$. virescens was significantly lower than the responses of individuals of the other species. Individuals of $C$. infraspinatus responded to introduction of conspecific hemolymph with an increase in both locomotion and the frequency of grasping of shells. C. infraspinatus also responded to the hemolymph of the other three species, and there were no differences in the magnitude of the responses depending upon the source of the hemolymph. When individuals of $C$. infraspinatus were exposed to snail odor and conspecific hemolymph at the same time. the responses were indistinguishable from those shown to hemolymph alone.
\end{abstract}

Key Words-Hermit crabs, odors, snail odor, hemolymph, Chibanarius spp.. Diogenes avarus, gastropods, crustaceans.

\section{INTRODUCTION}

The variety of ways that hermit crabs find and obtain appropriate gastropod shells for occupation is impressive. The use of chemical cues to locate potential shells for occupation has been particularly well studied in recent years (Hazlett and Hermkind, 1980; Kratt and Rittschof, 1991; Rittschof, 1980a,b; Rittschof et al., 1990). Two main categories of shell-related cues have been investigated: 
cues emanating from the degradation of snail flesh and cues associated with conspecific hemolymph. The latter would be released in the environment in the event of the death or injury of another hermit crab, which may indicate to hermit crabs that a shell is available for occupation. Injury-related cues work both intraspecifically to stimulate the investigation of the shells of other hermit crabs and to a lesser extent across species (Rittschof et al., 1992). Odor cues from damaged conspecifics are effective for both aquatic and terrestrial species (Small and Thacker, 1994; Thacker, 1994).

Cues from the degradation of snail flesh stimulate both an increase in locomotory behavior and an increase in the frequency of grasping of other shells by hermit crabs (Hazlett, 1979; McLean, 1974; Rittschof et al., 1992). At least in Clibanarius vittatus, the grasps are very brief unless the shell grasped is the same species as that indicated by the odor and is unoccupied (Hazlett and Rittschof, 1996). The response to conspecific hemolymph is also an increase in locomotion and frequency of grasping behavior, but with this cue the grasps tend to be longer in duration and more readily involve full investigation of a shell even if occupied (Hazlett, 1996a). Responses to both cues tend to be stronger when crabs occupy shells that are either too small or too large (Katz and Rittschof, 1993; Rittschof et al., 1992).

The vast majority of the reports on responses to these types of chemical cues have been on species common in the intertidal areas along the east coast of the United States, especially Clibanarius vittatus, as well as Pagurus pollicaris and Pagurus longicarpus (McLean, 1974; Rittschof, 1980a,b). While the responsiveness of these species to cues is well established, it is of interest to compare the types of responses shown by those species to that of other species of hermit crabs to examine the generality of this category of shell-acquiring behavioral responses and to look for differences in responses among species and to relate them to either phylogeny or ecological differences. In addition, the responses of individuals of one species of hermit crab to the hemolymph from a series of sympatric Australian species were studied to look at the question of what factors limit the degree of cross-species reactivity. Finally, the responses of individuals of Clibanarius infraspinatus were recorded when two inputs were presented simultaneously and compared to those recorded when single inputs were presented to examine the nature of stimulus integration.

\section{METHODS AND MATERIALS}

Observations were made in the laboratory at James Cook University, Townsville, Queensland, Australia, during February and March 1995. The behavior of crabs was recorded before and after exposure to potential chemical cues from either snails, hermit crabs, or both. The crabs used were all intertidal 
species in the Family Diogenidae, and all were collected at Rowes Bay, Townsville, Queensland, and transported to the laboratory. Crabs of a particular species were held in aquaria prior to being placed in round plastic dishes for observations of behavior patterns.

The species tested with snail odor (see below) were Clibanarius infraspinatus, Clibanarius taeniatus, Clibanarius virescens, and Diogenes avarus. C. virescens is found in rocky intertidal areas, while the other three species are from sandy, mudflat areas that are often divided into narrow pools at low tide (Haig and Ball, 1988). In addition to tests with snail odors, responses of individuals of Clibanarius infraspinatus were recorded following addition of conspecific hemolymph, hemolymph from other species of hermit crabs, and a combination of conspecific hemolymph and snail odor.

In all tests, sets of four crabs at a time were placed in an observation dish $(21 \mathrm{~cm}$ in diameter) filled to a depth of $2.5 \mathrm{~cm}$ with seawater and the bottom covered with about $1 \mathrm{~cm}$ of clean sand. These opaque dishes were rinsed in running seawater between each trial. Imaginary lines across the dish connecting marks on the sides of the dishes divided the bottom surface into four quarters. After a 1-min acclimation period, I recorded the number of lines crossed by the four crabs during a 3-min observation period and the number of times any crab grasped the shell of another crab with its walking legs. The grasps were categorized as long (lasting more than $1 \mathrm{sec}$ ) or brief (lasting about $1 \mathrm{sec}$ ) because work with another species of hermit crab indicated that different length grasps were executed depending upon the type of stimulus detected.

Each set of four crabs was tested first with a control solution of seawater added to the observation dish, and then test solution(s) were added and records of locomotion and grasping were made for $3 \mathrm{~min}$. For each test and control solution, between 16 and 20 replicate sets of four crabs were utilized for each species.

Snail odor was prepared by the freeze-thaw technique of Rittschof (1980b). utilizing $10 \mathrm{~g}$ of snails in $200 \mathrm{ml}$ of seawater. The snail flesh in seawater was frozen overnight and allowed to thaw to room temperature for use on a day of testing. The supernatent, which will be referred to as snail odor, was drawn off as needed for tests. While this solution contained a variety of gastropod products, Kratt and Rittschof (1991) have demonstrated that the shell-related responses to such a solution are the same as the responses to solutions generated by the action of digestive enzymes from snail predators acting on snail muscle. The snails used were a mixture of Thais leuterstoma and Morula marginalba. These are common intertidal gastropods in Rowes Bay, and the shells are occupied by some individuals of all the species tested. In all snail odor tests, $1 \mathrm{ml}$ of the test solution was introduced into the observation dish.

Hermit crab odor solutions were prepared by crushing $3.2 \mathrm{~g}$ of the appropriate species of hermit crab and mixing the flesh with $50 \mathrm{ml}$ of seawater. 
Rittschof et al. (1992) demonstrated that the shell-related behavior patterns shown by hermit crabs exposed to damaged conspecific individuals were in response to peptides in conspecific hemolymph. Therefore, although the preparations used in this study contained a variety of hermit crab chemicals, the preparations will be referred to as hemolymph. Because the hermit crab species differ in size, the number of individuals used to make up the solutions varied: one individual of $C$. infraspinatus, two of $C$. taeniatus, six of $C$. virescens, and 18 of $D$. avarus. One milliliter of the test solution was introduced into the observation dish for each test.

The responses of individuals of $C$. infraspinatus to the introduction of the conspecific hemolymph solution in their field-collected shells was very weak compared to the responses shown by individuals of other species tested ( $C$. vittatus) (Hazlett, 1996a; Rittschof et al., 1992). Therefore, to increase the shellrelated motivation of crabs, the shell apertures of 30 individuals were clipped back with a pair of pliers to make the shells smaller than desired by those size crabs (Katz and Rittschof, 1993). These crabs with clipped shells were tested with conspecific hemolymph, and these same individuals were utilized in tests with all remaining hermit crab preparations. In addition, these crabs were tested with a combination of snail odor and conspecific hemolymph introduced simultaneously.

Initially to look for an effect of the introduction of potential chemical cues, the behavioral scores during the control period (seawater introduction) and test period were compared by paired $t$ tests. In order to compare the magnitude of the response of the various species, the difference between scores on locomotion and grasping during the control and test period was calculated for each replicate, and these scores were compared across species by ANOVA. In some cases, individual contrasts (Wilkinson, 1988) were used to determine which treatments or species were different from one another.

\section{RESULTS}

Individuals of all four of the species tested with snail odors responded to introduction of the snail solution, but there were differences among the species. Diogenes avarus showed an increase in locomotion $(t=3.2, d f=19 ; P=$ 0.005 ), but none of the other species showed a change in the rate of locomotion, although there was a trend toward increased locomotion for $C$. virescens $(t=$ 2.06, $d f=15 ; P=0.057$ ) (Figure 1). All four species showed a significant increase in the number of brief grasps and in the number of long grasps executed following the introduction of the snail odor (Figure 1). However, there were differences between the species in the frequency of this grasping response to snail odor introduction (Figure 2). When the differences between test and control 


\section{(A) LOCOMOTION}

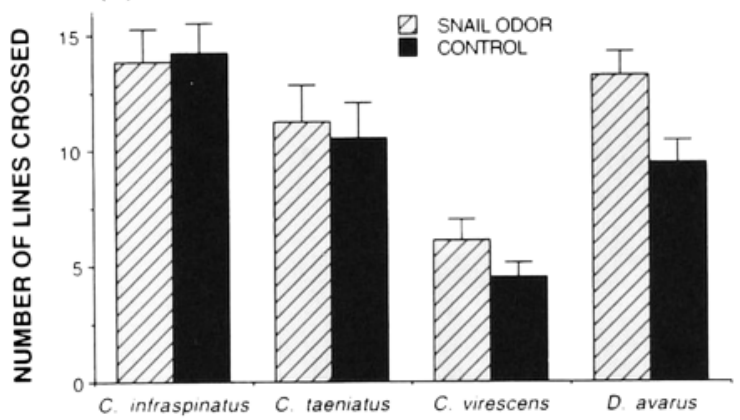

(B) BRIEF GRASPS



(C) LONG GRASPS

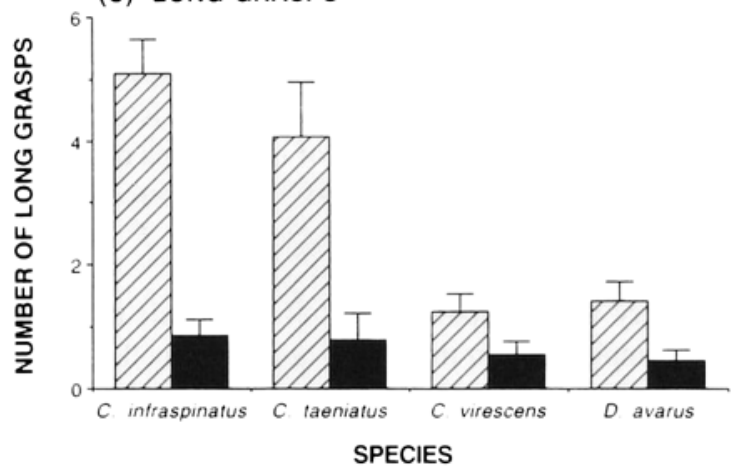

Fio. 1. Scores for behavional parameters (means + standard errors) during introduction of seawater control (black bars) and snail odor (crosshatched bars) for four species of Australian hermit crabs. 


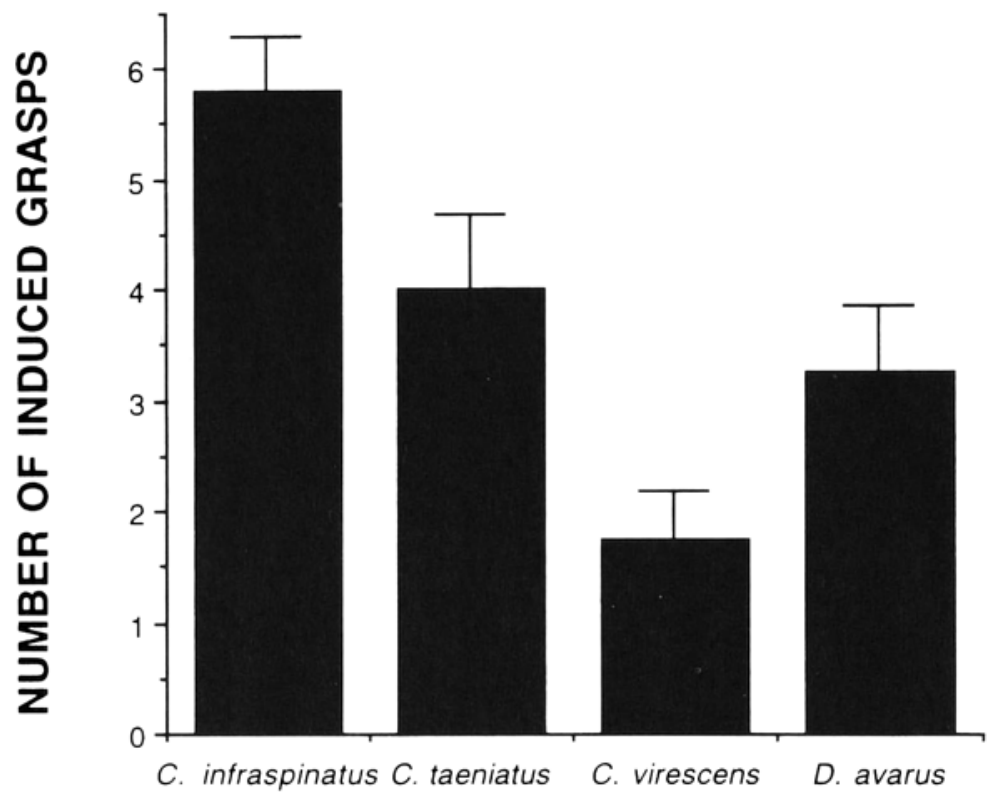

\section{SPECIES}

Fio. 2. Difference (mean + standard error) between number of grasps by individuals of four species of hermit crabs during control water and snail odor introductions.

periods for brief grasps and long grasps were summed for each replicate and the species compared, there were significant differences (ANOVA $F=20.3$. $d p=4,78 ; P<0.001$ ). This difference apparently is a result of the weaker response (although statistically significant) of individuals of $C$. virescens to snail odor (individual comparisons of $C$. taeniatus vs. $C$. virescens yielded $F=29.6$, $d p=1,78 ; P<0.001 ; C$. virescens vs. $D$. avarus, $F=5.23, d p=1.78$; $P=0.023$ ).

There were very weak responses of the individuals of $C$. infraspinatus to conspecific hemolymph when in their field-collected shells. None of the behavioral parameters showed a significant difference between test and control periods ( $t$ test values associated with $P>0.05$ ). Following the clipping of the shell apertures, these crabs did show a strong response to conspecific hemolymph with regards to increases in locomotion $(t=5.89, d f=14 ; P<0.001)$ and in both types of grasping behavior (brief grasps, $t=2.43, d f=14 ; P=0.029$; long grasps, $t=3.23$. $d f=14 ; P=0.006$ ) (Figure 3 ). The responses of individuals of $C$. infraspinatus to test solutions prepared from the other species 


\section{(A) LOCOMOTION}

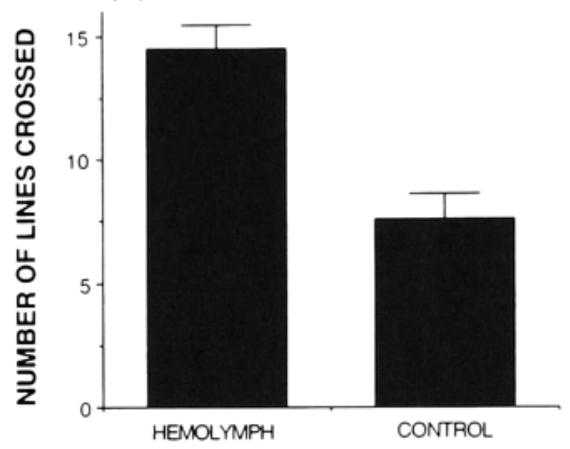

(B) BRIEF GRASPS

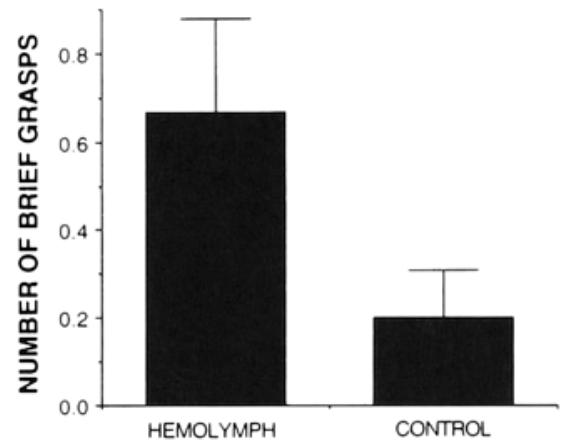

(C) LONG GRASPS

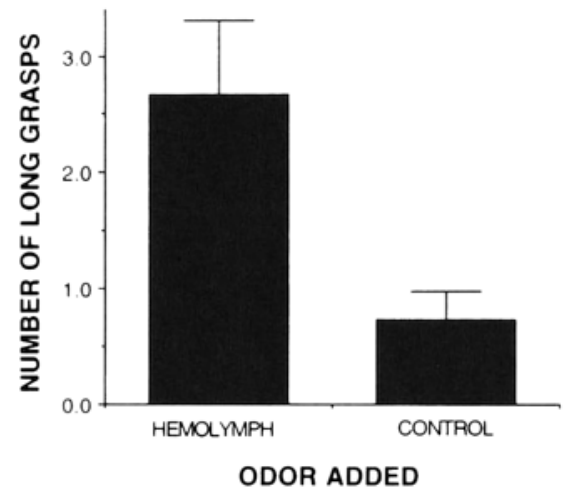

FIG. 3. Behavioral scores (mean + standard error) for individuals of Clibanarius infraspinatus during control water and conspecific hemolymph introductions. 
Table 1. Results of Statistical Tests Comparing Behavioral Responses of Clibanarius infraspinatus INDIVIDUALS TO CONTROL. AND TEST SOLUTIONS.

\begin{tabular}{|c|c|c|c|c|c|c|c|}
\hline \multirow{3}{*}{$\begin{array}{l}\text { Source of } \\
\text { hemolymph }\end{array}$} & \multirow[b]{3}{*}{ df } & \multicolumn{6}{|c|}{ Behaviors Recorded } \\
\hline & & \multicolumn{2}{|c|}{$\begin{array}{l}\text { Rate of } \\
\text { locomotion }\end{array}$} & \multicolumn{2}{|c|}{ Brief grasps } & \multicolumn{2}{|c|}{ Long grasps } \\
\hline & & $t$ & $P$ & i & $P$ & $t$ & $P$ \\
\hline C. infraspinatus & 14 & 5.89 & $<0.001$ & 2.43 & 0.029 & 3.23 & 0.006 \\
\hline C. raenialus & 14 & 4.76 & $<0.001$ & 4.02 & 0.001 & 2.88 & 0.013 \\
\hline C. virescens & 15 & 5.42 & $<0.001$ & 1.87 & 0.082 & 3.37 & 0.005 \\
\hline Diogenes avarus & 19 & 4.67 & $<0.001$ & 1.60 & 0.131 & 6.57 & $<0.001$ \\
\hline
\end{tabular}

"Test solutions were made using the hemolymph from different species of sympatric hermit crabs

of hermit crabs were also significantly different between test and control periods for every species (Table 1) for at least the rate of locomotion and the number of long grasps [which are the more typical responses shown to hemolymph (Hazlett, 1996a)]. There were no differences among the species as sources of input for individuals of $C$. infraspinatus (Figure 4). Testing the magnitude of the difference between test and control periods, there were no species effects on the magnitude of increase in locomotion (ANOVA $F=2.20, d f=6,92 ; P=$ $0.098)$, frequency of brief grasps $(F=1.62, d f=6,92: P=0.195)$, or frequency of long grasps ( $F=1.19, d f=6,92 ; P=0.323$ ). All of the diogenid species tested elicited responses of similar magnitude, although individual comparisons indicated that the scores for locomotion were significantly different between hemolymph from $C$. infraspinatus and $D$. avarus $(F=5.93, d f=1$, 92: $P=0.018$ ).

When individuals of $C$. infraspinatus were stimulated with both snail odor and conspecific hemolymph at the same time, they showed responses characteristic of hemolymph alone (Figure 5). A comparison of the three conditions (snail alone, hemolymph alone, combination) yielded a very significant difference among treatments for change in locomotion $(F=6.23, d f=1,43 ; P=$ $0.004)$ and change in the frequency of long grasps $(F=5.94, d f=1,43 ; P$ $=0.005)$. There was no effect on brief grasps $(F=1.26, d f=1,43 ; P=$ 0.294 ). Individual comparisons showed that for locomotion and long grasps there were significant differences between hemolymph and snail and between the combination stimulus and snail odor (all $P<0.01$ ), but no difference between the combination and hemolymph $(P>0.60)$. Both of the odors stimulated grasping and increases in locomotion when presented alone but they did not at all sum together in their effects when presented at the same time. 


\section{(A) LOCOMOTION}

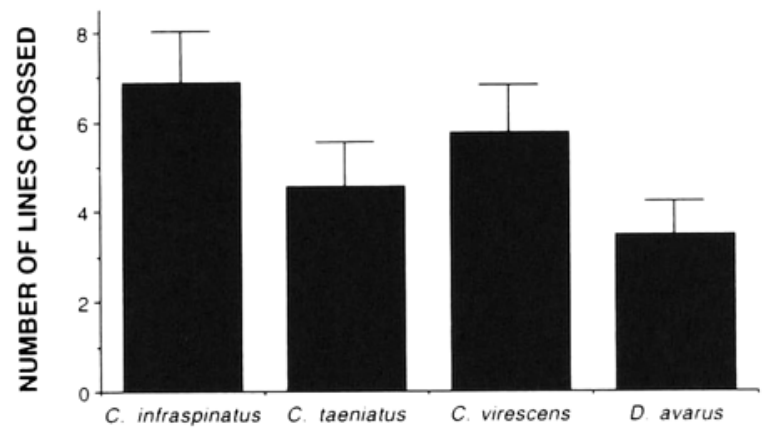

(B) BRIEF GRASPS

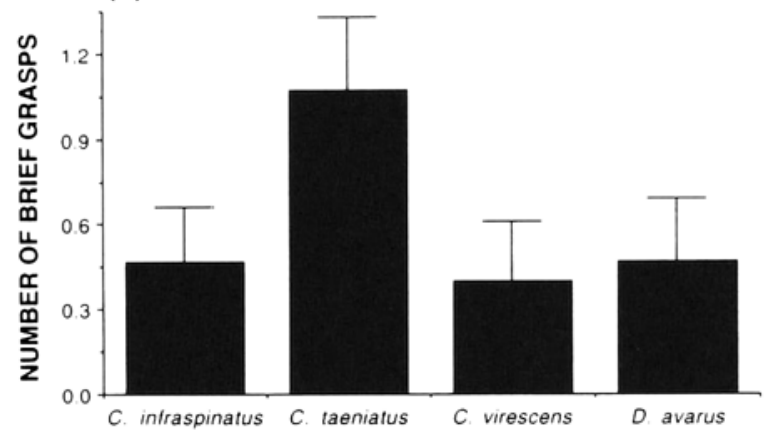

(C) LONG GRASPS

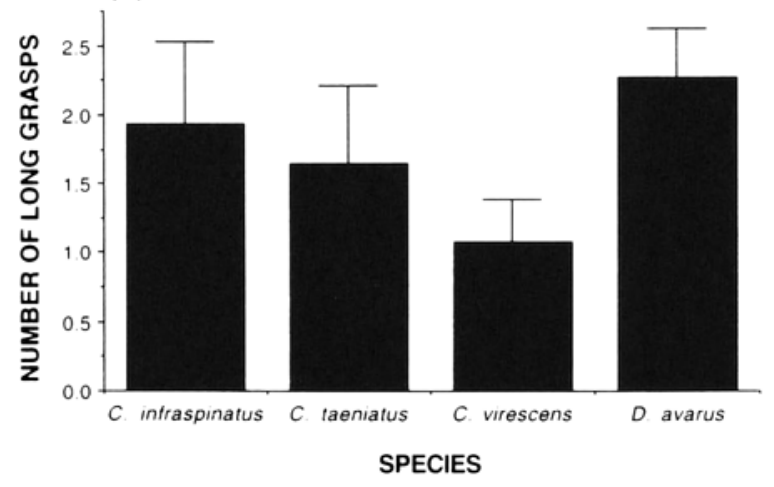

Fig. 4. Difference (mean + standard error) in behavioral scores for individuals of $C$. infraspinatus between control water introductions and introduction of the hemolymph of four species of hermit crabs. 
(A) LOCOMOTION

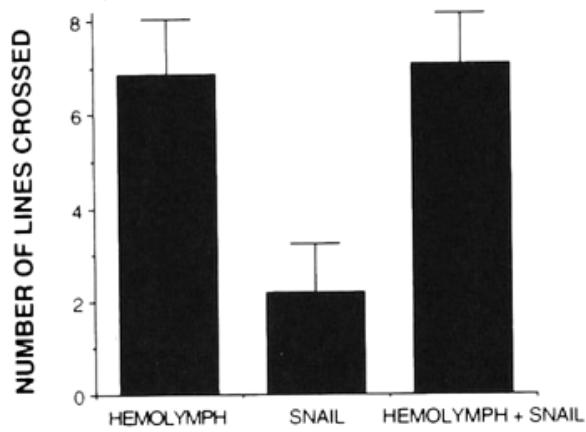

(B) BRIEF GRASPS



(C) LONG GRASPS

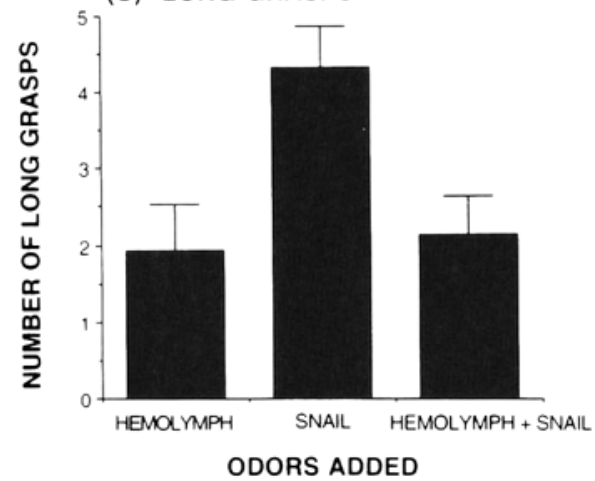

FlG. 5. Difference (mean + standard error) in behavioral scores for individuals of $C$. infraspinatus during control water and test odor introductions. 


\section{DISCUSSION}

The use by hermit crabs of chemical cues that increase their chances of finding an empty gastropod shell is clearly widespread. In addition to species found along the southeastern coast of the United States, all four of the species tested in Australia showed strong responses to odors from degraded snail flesh. Given the importance of the shell resource to hermit crabs (Hazlett, 1981), the use of an accurate indicator of empty shells is understandable.

While all four Indo-Pacific species showed a significant response to snail odor, the variation in the strength of the response is quite interesting. The lack of an increase in locomotion after detecting snail odor shown by several of the species is puzzling since an increase in locomotion is one of the responses reported for other species (Hazlett, 1996a). The large increase in the number of long grasps induced by snail odor in $C$. infraspinatus and $C$. taeniatus, compared to the more modest (but significant) increase shown by individuals of $C$. virescens and $D$. avarus, is somewhat surprising, because this pattern is different than the responses of $C$. vittatus studied in North Carolina (Hazlett, 1996a), which physically most closely resembles $C$. infraspinatus and $C$. taeniatus. The pattern of a more marked increase in brief grasps shown by $D$. avarus and $C$. virescens is similar to that shown by $C$. vittatus. However, this may reflect something as simple as the generally slower movement of $C$. infraspinatus and C. taeniatus as compared to the other species.

The total number of grasps induced by detection of snail odor was significantly weaker for one species ( $C$. virescens). This is the only species commonly found in a different habitat, the rocky intertidal zone, compared to the other species tested. Clibanarius infraspinatus, $C$. taeniatus, and Diogenes avarus (this study), as well as $C$. vittatus, Pagurus longicrapus, and $P$. pollicaris (McClean, 1974; Rittschof, 1980a), all inhabit sloping sandy beaches or mudflat areas. These areas would seem to have greater opportunities for orientation to sources of chemical cues due to the more predictable pattems of water movement at low tide as compared to the rocky intertidal zone. Preliminary field observations on Calcinus tibicen in the Caribbean and Calcinus elegans in Hawaii (both from rocky intertidal areas) also indicated a low level of responsiveness to snail odor (Hazlett, unpublished observations) compared to the species from sandy beaches. An altemative that cannot be ruled out with the data available is that crabs in rocky intertidal areas are in better-fitting shells and thus are less responsive to shell-related odor cues.

The responses of individuals of Clibanarius infraspinatus to preparations containing conspecific hemolymph adds to the list of hermit crabs that show a shell-related response to this type of chemical cue. Hermit crabs in poorly fitting shells respond to conspecific hemolymph by grasping nearby gastropod shells (Rittschof et al., 1992) and investigating them, i.e., executing grasps that are 
Iong in duration (Hazlett, 1996a). In this study, the surprising result is the similarity of responses by individuals of $C$. infraspinatus to solutions containing hemolymph from other species. Even though one of the species lives in a different habitat $(C$. virescens) and one is in a distantly related diogenid genus (Diogenes avarus), the overall response level to the different solutions was very similar. This is in contrast to the results reported by Rittschof et al. (1992), in which $C$. vittatus did not respond at all to hemolymph from two Pagurus species that live in the same area and the responses of the Pagurus species were much weaker to hemolymph from other than conspecifics. It is possible this results from greater phylogenetic differences in the case of diogenid and pagurid species since they are in different families. Some have suggested that these two families represent separate evolutions of the hermit crab life-style (McDonald et al., 1957), although McLaughlin (1983) has argued for monophyly. This possible explanation can also apply to the results of Thacker (1994) on terrestrial species where Coenobita compressus (Family Coenobitidae) responded just as strongly to conspecific hemolymph odors and odors from the hemolymph of the congeneric species Coenobita clypeatus, but the land hermit crabs did not respond to the hemolymph of the aquatic diogenid species he tested. Since hermit crabs are rarely specialists on any particular shell type (Hazlett, 1981), it seems reasonable that any injured hermit crab is a potential source of an empty shell for almost any other hermit crab, irrespective of the species of crab.

The response of individuals of $C$. infraspinatus to the combination of hemolymph odor and snail odor are very similar to the responses shown by individuals of $C$. vittatus when presented with a combination of inputs (Hazlett, 1996a; Rittschof and Hazlett, unpublished data). In both species, hemolymphrelated responses seemed to overnule any snail-induced responses. While shellseeking responses to detection of conspecific (or other hermit crab) hemolymph are shown only by crabs in poorly fitting shells (Rittschof et al. 1992), those crabs appear to be more strongly influenced by that cue than by the more specific cue resulting from degradation of snail flesh. While it is possible that in both studies reporting this result, the concentration of the hemolymph cue was stronger than the concentration of the snail cue, there is an alternative explanation. The hemolymph cue, while indicating some degree of danger, is a more general signal of shell availability since the potentially empty shell can be any species of shell in the area, while the snail flesh cue provides information on the potential availability of a single species of shell. While detection of one cue frequently inhibits the responses associated with another cue, the hierarchy of influence is usually one of predator cues overruling resource-related cues (Hazlett, 1996a,b; Mitchell and Hazlett, 1996). In this study, the inhibition is by the more reliable of the resource-related cues.

Acknowledgments--I wish to thank the staft at James Cook University for their assistance in making this study possible. Patsy McLaughlin for confirmation of species identification, and Catherine Bach and Dan Rittschof for their comments on the manuscript. 


\section{REFERENCES}

HAIG. J., and BALL, E. E. 1988 . Hermit crabs from North Australian and eastem Indonesian waters (Crustacea Decapoda: Anomura: Paguroidea) collected during the 1975 Alpha Helix expedition. Rec. Aust. Mus. 40:151-196.

HA/LET, B. A. 1979. Individual distance in crustacea: IV. Distance and dominance hierarchies in Pagurus pollicaris. Mar. Behar, Physiol. 6:225-242.

HAZLETT, B. A. 1981. The behavioral ecology of hermit crabs. Anmu. Rev. Ecol. Sysr 12:1-22.

HAZLETT, B. A. 1996a. Organisation of hermit crab behaviour: Responses to multiple chemical inputs. Behaviour 133:619-642.

HAZLET, B. A. 19966. The organisation of behaviour in hermit crabs: Responses to variation in stimulus strength. Behaviour In press.

HAZLETT, B. A., and HERRNKIND, W. 1980 . Orientation to shell events by the hermit crab Clibanarius vitlatus (Bosc) (Decapoda, Paguridea). Crustaceana 39:311-314.

HAZLETT, B. A., and RitrsCHOF, D. 1996. Multiple mechanisms of resource acquisition in hermit crabs: scrums and odor-induced grasping. Crustactana. In press

KAT/. J. N., and RitrschoF, D. 1993. Alarm/investigation responses of hermil crabs as related to shell fit and crub size. Mar. Behos, Phywol. 22:171-182

KratT, C. M. and RItTschoF. D. 1991. Peptide attraction of hermit crabs Clibanarius vistamus Bosc: Roles of enzymes and substrates. J. Chem. Eowl. 17:2347-2365.

MacDonald, J. D.. Pike, R. B.. and Williamson, D. I. 1957. Laryae of the British species of Diogenes. Pagurus, Anapagurus, and Lithroles (Crustacea, Decapoda). Proc. Zool. Soc. Lomdom 128:209-257

MCLeAN. R. B. 1974. Direct shell acquisition by hemit crabs from gastropods. Experientia 30:206208.

MClaughin, P. A. 1983. Hermit crabs-are they really polyphyletic? J. Crusi. Biol. 3:608-621.

MitchelL, B.. and HazLetT. B. A. 1996. Predator avoidance strategies of the crayfish Oromectes virilis. Crustaceana 69:400-412.

RittsChOF, D., 1980a. Chemical attraction of hermit crabs and other attendants to simulated gastropod predation sites. J. Chem. Ecel 6:103-118.

Ritrschof, D. 1980b. Enzymatic production of small molecules attracting hermit crabs to simulated gastrupod predation sites. $J$. Chem. Ecol. 6:665-675.

Rittschof, D. KratT, C. M.. and Clare. A. S. 1990. Gastropod predation sites: the role of predator and prey in chemical attraction of the hermit crab Clibanarius vimanus. J. Mar. Biol. Assoc. U.K. 70:583-596.

Rittschof, C., Tsai, D. W.. Massey, P. G., Blanco, L., Kufber, G. L., Jr., and haas, R. J., Jr. 1992. Chemical mediation of behavior in hermit crabs: alam and aggregation cues. $J$. Chem. Ecrl. 18:959-984.

SMALL. M. P.. and THACKF, R. W. 1994. Land hermit crabs use odors of dead conspecifics to locate shells. J. Exp. Mar. Biol. Ecol. 182:169-182.

THACKER, R. W. 1994. Volatile shell-investigation cues of land hermit crabs: effect of shell hit. detection of cues from other hermit crab species, and cue isolation. J. Chem. Ecot. 20:14571482.

WILkinson, L. 1988. Systat, the System for Statistics. Systut Inc., Evanston, Mlinois, 